\title{
Novel Positron Emission Tomography Tracers for Imaging Vascular Inflammation
}

\author{
Andrej Ćorović $^{1} \cdot$ Christopher Wall $^{1}$ • Justin C. Mason ${ }^{2} \cdot$ James H. F. Rudd $^{1} \cdot$ Jason M. Tarkin ${ }^{1,2}$ (I) \\ Published online: 9 August 2020 \\ (C) The Author(s) 2020
}

\begin{abstract}
Purpose of Review To provide a focused update on recent advances in positron emission tomography (PET) imaging in vascular inflammatory diseases and consider future directions in the field.

Recent Findings While PET imaging with ${ }^{18}$ F-fluorodeoxyglucose (FDG) can provide a useful marker of disease activity in several vascular inflammatory diseases, including atherosclerosis and large-vessel vasculitis, this tracer lacks inflammatory cell specificity and is not a practical solution for imaging the coronary vasculature because of avid background myocardial signal. To overcome these limitations, research is ongoing to identify novel PET tracers that can more accurately track individual components of vascular immune responses. Use of these novel PET tracers could lead to a better understanding of underlying disease mechanisms and help inform the identification and stratification of patients for newly emerging immune-modulatory therapies. Summary Future research is needed to realise the true clinical translational value of PET imaging in vascular inflammatory diseases.
\end{abstract}

Keywords PET $\cdot$ Inflammation $\cdot$ Atherosclerosis $\cdot$ Large-vessel vasculitis $\cdot$ Molecular imaging $\cdot$ Non-invasive imaging

This article is part of the Topical Collection on Nuclear Cardiology

Jason M. Tarkin

jt545@cam.ac.uk

Andrej Ćorović

ac476@cam.ac.uk

Christopher Wall

cw463@cam.ac.uk

Justin C. Mason

justin.mason@imperial.ac.uk

James H. F. Rudd

jhfr2@cam.ac.uk

1 Division of Cardiovascular Medicine, University of Cambridge, Cambridge, UK

2 Cardiovascular Division, National Heart \& Lung Institute, Imperial College London, London, UK

\section{Introduction}

Inflammation is the cause or consequence of many cardiovascular diseases. In particular, inflammation is central to the pathogenesis of atherosclerosis [1], the most common cause of myocardial infarction and ischaemic stroke. Large-vessel vasculitis (LVV) is another important vascular inflammatory disease, which is associated with progressive arterial injury and accelerated coronary atherosclerosis.

Non-invasive imaging is a key component of the diagnostic and disease-monitoring pathways for these cardiovascular inflammatory diseases. While echocardiography, CT, MRI, and nuclear perfusion imaging are first-line non-invasive cardiac investigations, positron emission tomography (PET) imaging of inflammation can also play an important clinical role. Moreover, advances in cardiovascular PET imaging research and technology, including hybrid PET/MRI and total body PET, may open new clinical translational avenues in the near future.

In atherosclerosis, vascular inflammation detected by PET may serve as a marker of high-risk plaques or overall heightened disease activity. This approach could be particularly important in the post CANTOS (Canakinumab Antiinflammatory Thrombosis Outcome Study) [2••] and 
COLCOT (Colchicine Cardiovascular Outcomes Trial) [3••] era, either as a means of testing drug efficacy in clinical trials or identifying and stratifying groups of individuals who would most benefit from novel anti-inflammatory therapies. Moreover, while PET imaging is already an established technique for diagnosis of LVV, further research is needed to evaluate its role for tracking therapy responses and identifying individuals with residual or refractory disease that require treatment escalation.

This article aims to provide a focused update on recent research relating to PET imaging of vascular inflammation in atherosclerosis and LVV. Specifically, we will highlight three key areas of ongoing research that may be the most clinically relevant in coming years:

i) Evaluation of novel PET tracers for imaging specific components of the vascular immune response

ii) Use of PET imaging in the clinical trials pipeline to gain early insights about drug efficacy

iii) Investigation of PET imaging for identification and stratification of high-risk patients for emerging immunomodulatory therapies.

\section{${ }^{18}$ F-FDG PET Imaging of Vascular Inflammation}

PET "tracers" are ligands or molecules of interest that are labelled with positron emitting radionuclides, allowing them to be localised in the body after injection by the detection of gamma rays, the by-product of annihilation events occurring when a positron encounters an electron. While PET is extremely sensitive, it has poor spatial resolution, and hence, integrated PET scanners are used to co-register PET images with CT or MRI for accurate anatomical localisation. The great advantage of PET as a molecular imaging technique lies in its ability to target specific pathologic features or processes of interest.

${ }^{18} \mathrm{~F}$-fluorodeoxyglucose (FDG) is the most commonly used PET tracer, both in clinical practice and research relating to vascular inflammation. As a radiolabelled glucose analogue, ${ }^{18} \mathrm{~F}$-FDG is taken up by all metabolically active cells that rely on glucose as a substrate, including macrophages and other inflammatory cells (e.g. neutrophils and lymphocytes). Stemming from the initial proof-of-principle study to evaluate ${ }^{18}$ F-FDG for imaging carotid artery inflammation [4], a surfeit of studies have confirmed the utility of this tracer in atherosclerosis imaging. Indeed, numerous studies have confirmed a strong correlation between ${ }^{18} \mathrm{~F}$-FDG uptake and histological markers of macrophage density in atherosclerotic plaques, as well as clinical, biochemical, and gene expression markers related to inflammation. This topic has been comprehensively reviewed elsewhere $[5,6]$.

However, it is also clear that in certain scenarios, significant contributions to vascular PET signals arise from nonmacrophage glucose metabolising cells that may or may not be part of the inflammatory response. Moreover, because of avid physiological uptake of ${ }^{18} \mathrm{~F}$-FDG by cardiac myocytes, coronary imaging is precluded in up to $50 \%$ of patients with this tracer despite the use of stringent myocardial suppression protocols [7, 8]. For these reasons, alternative PET tracers for imaging vascular inflammation are being actively sought.

\section{Novel PET Tracers for Imaging Atherosclerosis}

In atherosclerosis, the search for PET tracers for imaging inflammation and related pathophysiological processes was initially focused on identifying high-risk or "vulnerable" atherosclerotic plaques. However, given the low positive predictive value of individual vulnerable plaque detection for prediction of future clinical events, the focus has now shifted towards identifying high-risk patients who may have a high burden of inflamed, vulnerable plaques. The histological features of high-risk plaques include a thin fibrous cap; high macrophage density; a large lipid-rich, necrotic, and hypoxic core; "spotty" microcalcification; and neo-angiogenesis. While several noninvasive and invasive imaging techniques are capable of identifying markers associated with histological findings of highrisk plaques, ${ }^{18} \mathrm{~F}$-FDG PET is the most widely studied method for detecting plaque inflammation [9].

Novel tracers for atherosclerosis imaging, of which many have been repurposed from oncology imaging, can be broadly categorised into those targeting inflammatory cells and those targeting adjunctive atherosclerotic processes. Some of the most promising approaches for imaging atherosclerosis-related vascular inflammation with PET to date are highlighted below. A more extensive list covering the range of PET tracers tested for vascular inflammation imaging is provided in Table 1.

\section{Tracers for Imaging Inflammatory Cells}

Inflammatory cells such as macrophages, which are fundamental to the pathogenesis of atherosclerosis, can be identified by various cell-surface markers or receptors. These markers have been utilised as imaging targets for several classes of PET tracers examined in atherosclerosis.

The translocator protein (TSPO) receptor is situated in the outer mitochondrial membrane and is highly expressed in activated cells of the mononuclear phagocyte lineage. In a study of 32 patients who underwent PET imaging with the TSPO radioligand ${ }^{11} \mathrm{C}-\mathrm{PK} 11195$, culprit carotid plaques associated with stroke or transient ischaemic attack where highlighted by the tracer [10]. In this study, ${ }^{11} \mathrm{C}-\mathrm{PK} 11195$ signals were 
Table 1 Novel tracers for vascular inflammation imaging

\begin{tabular}{|c|c|}
\hline Tracer & Molecular target/ \\
\hline
\end{tabular}

Atherosclerosis

Tracers for imaging inflammatory cells

${ }^{11} \mathrm{C}-\mathrm{PK} 11195[10] \quad$ TSPO

${ }^{18}$ F-FEDAA1106 [11]

Activated macrophages

${ }^{18}$ F-FEMPA [12]

${ }^{18}$ F-GE-180 [13]

${ }^{68} \mathrm{Ga}$-DOTATATE

$[14,18,19]$

${ }^{64} \mathrm{Cu}$-DOTATATE $[20,21]$

${ }^{68} \mathrm{Ga}$-DOTANOC [18]

${ }^{18} \mathrm{~F}-\mathrm{FDR}-\mathrm{NOC}[18]$

${ }^{68}$ Ga-DOTATOC $[21,22]$

${ }^{68}$ Ga-pentixafor [23-28]

${ }^{64} \mathrm{Cu}$-DOTA-DAPTA-comb nanoparticles [30]

${ }^{64} \mathrm{Cu}$-DOTA-ECL1i [31, 32]

${ }^{64} \mathrm{Cu}$-DOTA-vMIP-II [29]

${ }^{64} \mathrm{Cu}$-vMIP-II-comb nanoparticles [33]

${ }^{18}$ F-FOL [34]

${ }^{68}$ Ga-NOTA-MSA [35]

${ }^{18} \mathrm{~F}-\mathrm{FDM}[36]$

${ }^{64} \mathrm{Cu}-\mathrm{MMR}$ and ${ }^{68} \mathrm{Ga}-\mathrm{MMR}$ nanobodies [37]

${ }^{18}$ F-fluorothymidine [38]

${ }^{18} \mathrm{~F}$-fluoromethylcholine [39-41] Choline analogues

${ }^{11} \mathrm{C}$-choline [42]

${ }^{89} \mathrm{Zr}$-modified dextran nanoparticles [43], ${ }^{18}$ F-Macroflor [45]

$\mathrm{SST}_{2}$ and other somatostatin receptor sub-types

CXCR4

CCR5

CCR2

Chemokine receptors (multiple)

Folate receptor $\beta$ Mannose receptor

Thymidine analogue

Internalized by phagocytic myeloid cells

Tracers for imaging adjunctive atherosclerotic processes

${ }^{68}$ Ga-Fucoidan [46] P-selectin

${ }^{64} \mathrm{Cu}$-DOTA-anti-P-selectin antibodies [47]

${ }^{18} \mathrm{~F}-4 \mathrm{~V}$ [48]

${ }^{64} \mathrm{Cu}$-VCAM nanobody [37]

${ }^{64} \mathrm{Cu}-\mathrm{LOX}$ nanobody [37]

${ }^{89} \mathrm{Zr}-\mathrm{LA} 25$ [49]

${ }^{89} \mathrm{Zr}-\mathrm{HDL}$ nanoparticles [50]

${ }^{18} \mathrm{~F}-\mathrm{ML}-10$ [51]

${ }^{18} 18 \mathrm{~F}-\mathrm{NaF}$ [8]

${ }^{18} \mathrm{~F}-\mathrm{HX} 4$ [53]

${ }^{18}$ F-FMISO [54, 55]

${ }^{62} \mathrm{Cu}$-ATSM [56]

${ }^{18} \mathrm{~F}$-fluciclatide [57]

${ }^{18}$ F-Galacto-RGD [58, 59]

${ }^{18}$ F-Flotegatide [60]

${ }^{64} \mathrm{Cu}$-DOTA-C-ANF [61]

DOTA-CANF-comb nanoprobe [62]

${ }^{18} \mathrm{~F}$-florbetaben [63]

${ }^{18}$ F-flutemetamol [64]

\section{VCAM-1}

LOX-1 receptor for oxidised LDL

Oxidation-specific epitopes

High-density lipoprotein (HDL)

Cell membrane fragments

Hydroxyapatite

n/a (hypoxia markers)

Integrin $\alpha v \beta 3$

Natriuretic clearance receptors

Amyloid
Predominantly

"pro-inflammatory" M1

macrophages

Leukocytes, including monocytes/macrophages and lymphocytes

Monocytes/macrophages

Monocytes/macrophages

Monocytes/macrophages

Macrophages

Predominantly "reparative" M2 macrophages

Multiple cell types

(Cellular proliferation marker)

Multiple cell types (markers of phospholipid metabolism)

Predominately monocytes/macrophages

Endothelial cells

Endothelial cells

Endothelial cells, also macrophages and smooth muscle cells

$\mathrm{n} / \mathrm{a}$ (by-products of LDL oxidation)

Macrophages

Multiple cell types

$\mathrm{n} / \mathrm{a}$

$\mathrm{n} / \mathrm{a}$

Activated endothelial cells, also macrophages

Endothelial cells and vascular smooth muscle cells
Inflammatory cell recruitment/activity

،

,

,

6

‘,

,

,

،

,

Endothelial cell activation and margination of circulating monocytes and other inflammatory cells ',

Uptake of oxidised LDL, also inflammatory cell recruitment/activity

LDL oxidation

Cholesterol transport

Cellular apoptosis, especially of smooth muscle cells

Microcalcification

Hypoxia

Neo-angiogenesis, also inflammatory cell recruitment/activity

Neo-angiogenesis

Amyloid within plaque 
Table 1 (continued)

\begin{tabular}{|c|c|c|c|}
\hline Tracer & $\begin{array}{l}\text { Molecular target/ } \\
\text { mechanism }\end{array}$ & Cellular target & Biological process \\
\hline \multicolumn{4}{|l|}{ Large vessel vasculitis } \\
\hline${ }^{11} \mathrm{C}-\mathrm{PK} 11195[75,76]$ & TSPO & Activated macrophages & $\begin{array}{l}\text { Granuloma formation, } \\
\text { also inflammatory cell recruitment/activity }\end{array}$ \\
\hline $\begin{array}{l}{ }^{68} \text { Ga-DOTATATE [77] } \\
{ }^{18} \text { F-FET- } \beta \text { AG-TOCA [77] }\end{array}$ & $\mathrm{SST}_{2}$ receptors & $\begin{array}{l}\text { Predominantly } \\
\text { "pro-inflammatory" M1 } \\
\text { macrophages }\end{array}$ & ، \\
\hline
\end{tabular}

confirmed in macrophage-rich plaque areas when examined histologically [10]. Other TSPO tracers that have potentially lower non-specific binding than ${ }^{11} \mathrm{C}$-PK11195 and are less affected by genetic polymorphisms leading to variable receptor binding affinity are being investigated [11-13].

Upregulation of somatostatin receptor subtype-2 $\left(\mathrm{SST}_{2}\right)$ occurs in activated macrophages. Initial preclinical studies performed in mice, and retrospective analyses of imaging data from patients who underwent PET imaging as part of oncologic work-up, suggested that the $\mathrm{SST}_{2}$ PET ligand ${ }^{68} \mathrm{Ga}-$ DOTATATE could be useful for imaging vascular inflammation [14-18]. In a subsequent prospective clinical study of 42 patients with atherosclerosis, ${ }^{68} \mathrm{Ga}$-DOTATATE was found to accurately localise macrophage-related inflammation in atherosclerotic plaques when compared with histological and gene expression analyses. Unlike ${ }^{18} \mathrm{~F}-\mathrm{FDG}$, low physiological myocardial binding of this tracer permitted reliable analysis of the coronary vasculature [19•](Fig. 1a). Another study, of ${ }^{64} \mathrm{Cu}$-DOTATATE, also found this tracer to be useful for identifying carotid artery inflammation in patients with transient ischaemic attack and identified an association with gene expression of markers in macrophages [20]. Several other clinical somatostatin receptor binding tracers have also been examined for use in atherosclerosis imaging [18, 21, 22].

The C-X-C motif chemokine receptor type 4 (CXCR4) is expressed on the surface of several cell types involved in atherosclerosis, including macrophages and lymphocytes. ${ }^{68} \mathrm{Ga}$-pentixafor binding has been observed in macrophagerich excised carotid atherosclerotic plaques [23]. Increased arterial ${ }^{68} \mathrm{Ga}$-pentixafor PET signals have also been associated with the presence of clinical cardiovascular risk factors [24]. In a clinical study of 37 patients who underwent ${ }^{68} \mathrm{Ga}$ pentixafor PET after stent-based reperfusion for ST segment elevation myocardial infarction, PET signals were increased in culprit compared with non-culprit lesions [25•] (Fig. 1b). Other studies have also confirmed the utility of this tracer for atherosclerosis imaging [26-28].

PET tracers targeted at C-C chemokine receptor type 5 (CCR5), type 2 (CCR2), and other immune cell chemokine surface receptors have been evaluated in animal models of vascular injury and atherosclerosis [29-32]. In one study, the feasibility of imaging 8 chemokine receptors simultaneously was tested using targeted nanoparticles [33]. Folate receptor $\beta$ and the mannose receptor are other promising macrophage receptor targets that have been examined in preclinical studies [34-37].

Other approaches for imaging inflammation include PET tracers such as ${ }^{18} \mathrm{~F}$-fluorothymidine (FLT), ${ }^{18} \mathrm{~F}$ fluoromethylcholine, and ${ }^{11} \mathrm{C}$-choline, which provide markers of cellular proliferation and phospholipid metabolism [38-42]. In one study of 10 consecutive stroke patients scheduled for carotid endarterectomy, ${ }^{18} \mathrm{~F}$-fluoromethylcholine uptake was higher in symptomatic carotid arteries than the contralateral asymptomatic side and was significantly correlated with the degree of CD68 macrophage staining in endarterectomy specimens [41].

Radiolabelled nanoparticles, such as modified dextrans, which are directly internalised by myeloid phagocytic cells have also been successfully imaged using PET [43-45].

\section{Tracers for Imaging Adjunctive Atherosclerotic Processes}

Endothelial activation and margination of circulating monocytes and other inflammatory cells occur at an early state in the pathogenesis of atherosclerosis. P-selectin and vascular cell adhesion protein-1 (VCAM-1) are endothelial cell adhesion molecules involved in this process, which have been targeted by experimental PET tracers in preclinical studies [37, 46-48].

PET tracers have also been tested in preclinical atherosclerosis models for imaging cholesterol transport, markers of lowdensity lipoprotein (LDL) oxidation, and apoptosis, which lead to the formation of lipid-rich necrotic cores [37, 49-51].

Microcalcification is another important feature of atherosclerosis, which is associated with vulnerable plaques. Arterial microcalcification that is below the resolution of a CT scanner can be visualised by ${ }^{18} \mathrm{~F}-\mathrm{NaF}$, which binds to exposed hydroxyapatite. This tracer has been extensively evaluated for use in atherosclerosis imaging in recent years [52]. In a prospective clinical trial of 80 patients with myocardial infarction or stable angina, ${ }^{18} \mathrm{~F}-\mathrm{NaF}$ was able to better differentiate culprit from non-culprit coronary arterial plaques than ${ }^{18} \mathrm{~F}-\mathrm{FDG}$ and showed increased signals in stable lesions with high-risk plaque features confirmed by intravascular ultrasound [8]. 

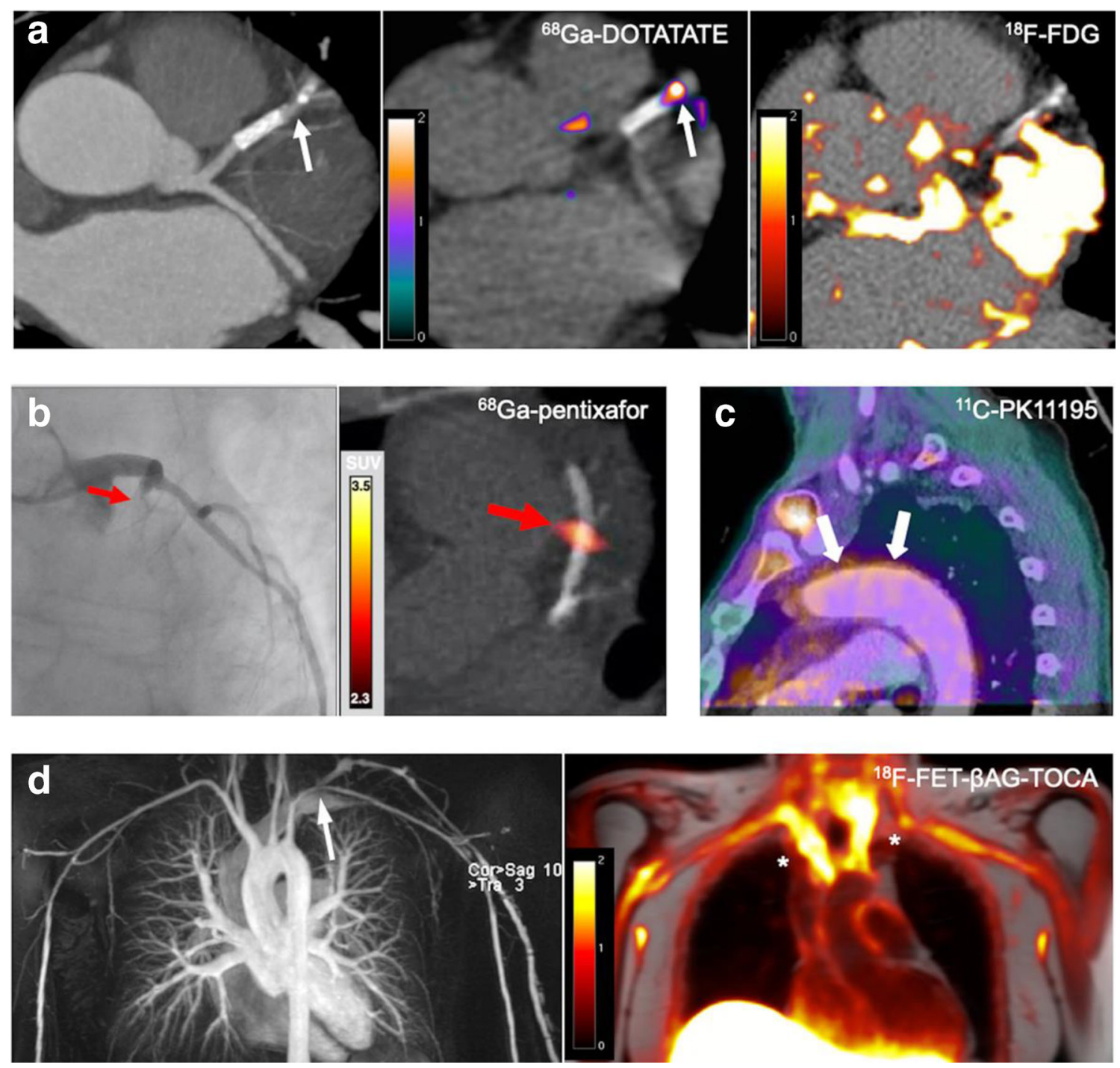

Fig. 1 PET imaging of vascular inflammation in atherosclerosis and large-vessel vasculitis. a CT coronary angiography (left panel), ${ }^{68} \mathrm{Ga}-$ DOTATATE (centre panel), and ${ }^{18} \mathrm{~F}-\mathrm{FDG}$ (right panel). PET/CT imaging in a patient with non-ST segment myocardial infarction due to a culprit left anterior descending artery lesion (arrow). While there is increased ${ }^{68} \mathrm{Ga}$-DOTATATE ( $\mathrm{SST}_{2}$ ) PET signal arising from the culprit coronary artery, accurate coronary ${ }^{18} \mathrm{~F}-\mathrm{FDG}$ image interpretation is precluded by diffuse background myocardial tracer uptake. (Reproduced from: Tarkin JM, et al. J Am Coll Cardiol 2017; 69:17741791; doi: https://doi.org/10.1016/j.jacc.2017.01.060; Creative Commons user licence https://creativecommons.org/licenses/by/4.0/) [19•]. b Coronary angiography (left panel) and ${ }^{68}$ Ga-pentixafor (CXCR4) PET/CT imaging (right panel) showing avid tracer uptake in a culprit left anterior descending artery lesion (arrow) of a patient with acute myocardial infarction. (Reproduced from: Derlin T, et al. J Nucl

Med Mol Img 2018; 45:1934-1944; doi.org/10.1007/s00259-018-40762; Creative Commons user licence https://creativecommons.org/licenses/ by/4.0/) [25•]. c ${ }^{11} \mathrm{C}-\mathrm{PK} 11195$ (TSPO) PET/CT imaging in a patient with active giant cell arteritis showing increased tracer uptake (arrows). (Reproduced from: Pugliese F, et al. J Am Coll Cardiol 2010;56(8): 653-61. doi: https://doi.org/10.1016/j.jacc.2010.02.063, with permission from Elsevier) [76]. d MR angiography (left panel) showing a chronic left subclavian stenosis (arrow) in a patient with treatmentresistant Takayasu arteritis. In this patient, ${ }^{18} \mathrm{~F}-\mathrm{FET}-\beta \mathrm{AG}-\mathrm{TOCA}$ $\left(\mathrm{SST}_{2}\right) \mathrm{PET} / \mathrm{MRI}$ demonstrates increased tracer signal in the affected vessels (asterisks). (Reproduced from: Tarkin JM, Circ Cardiovasc Imaging 2020;13(6):e010389; doi: https://doi.org/10.1161/ CIRCIMAGING.119.010389, with permission from Wolters Kluwer Health Inc.) [77]

Hypoxia is a feature of the lipid-rich necrotic core within plaques and contributes to angiogenesis in atherosclerosis. In two prospective clinical studies of patients with carotid artery disease who underwent PET imaging with either ${ }^{18} \mathrm{~F}-\mathrm{HX} 4$ or ${ }^{18}$ F-FMISO for measuring hypoxia, tracer uptake was increased in relation to carotid plaques identified by MRI and symptomatic carotid lesions, respectively [53, 54]. In both

studies, strong correlations were observed between PET markers of hypoxia and carotid arterial ${ }^{18} \mathrm{~F}-\mathrm{FDG}$ uptake, supporting prior data showing that hypoxia augments ${ }^{18} \mathrm{~F}$ FDG uptake in atherosclerotic plaques. Preclinical research performed using ${ }^{18} \mathrm{~F}$-FMISO and another hypoxia tracer, ${ }^{62} \mathrm{Cu}-\mathrm{ATSM}$, in rabbit models of atherosclerosis is also consistent with these findings in patients $[55,56]$. 
It may also be possible to image neo-angiogenesis relating to high-risk atherosclerotic plaques by targeting integrins, such as $\alpha v \beta 3$, with PET ligands. Integrin $\alpha \mathrm{v} \beta 3$ is expressed by activated endothelial cells, as well as macrophages. In a study of 46 patients with atherosclerosis who underwent PET imaging with the $\alpha v \beta 3$ tracer ${ }^{18} \mathrm{~F}$-fluciclatide, uptake of this tracer in the aorta was higher in patients with myocardial infarction than stable angina and was correlated with measures of aortic atherosclerotic burden [57]. Other $\alpha v \beta 3$-targeted tracers that have been evaluated for use in atherosclerosis include ${ }^{18} \mathrm{~F}$-Galacto-RGD and ${ }^{18} \mathrm{~F}$ Flotegatide [58-60]. The imaging of natriuretic clearance receptors, which in atherosclerosis are upregulated in endothelial cells as well as vascular smooth muscle cells, has also been tested in preclinical studies [61, 62].

Amyloid $\beta$ peptides represent another potential atherosclerosis imaging target, as these peptides exist within human atherosclerotic plaques. Vascular deposition of amyloid $\beta$ is associated with inflammatory changes in the vessel wall and microvasculature and could contribute to the known link between cardiovascular disease and Alzheimer's disease. The feasibility of amyloid PET imaging in carotid arterial atherosclerosis has been demonstrated using ${ }^{18} \mathrm{~F}$-florbetaben and ${ }^{18}$ F-flutemetamol [63, 64].

\section{Novel PET Tracers for Imaging Large-Vessel Vasculitis}

LVV comprises a group of chronic, systemic granulomatous diseases, including giant cell arteritis and Takayasu arteritis, which lead to progressive injury of the aorta and its main branches, affecting the organs and limbs supplied. The use of ${ }^{18}$ F-FDG PET to confirm the diagnosis of active LVV in the extracranial vessels is well-established in clinical practice and supported by international guideline recommendations [65-67]. Indeed, a meta-analysis of 298 patients from 9 studies showed that ${ }^{18}$ F-FDG PET demonstrated a pooled sensitivity of $88 \%$ and specificity of $81 \%$ for diagnosis of LVV [68]. However, it is important to note that the diagnostic accuracy of ${ }^{18} \mathrm{~F}$-FDG PET for LVV is significantly reduced after high-dose steroids which are given for more than 3 days [69]. Although the use of ${ }^{18} \mathrm{~F}$ FDG for the detection of temporal arteritis in GCA or coronary involvement in Takayasu arteritis is often hampered by background tracer uptake from the brain and myocardium, respectively, a study of 64 patients found ${ }^{18}$ F-FDG PET to be accurate for biopsy-proven temporal arteritis [70]. As well as confirming the diagnosis, ${ }^{18}$ F-FDG PET imaging reveals the distribution of affected arteries and can identify areas of pre-stenotic disease to prompt early intervention.

However, the utility of ${ }^{18} \mathrm{~F}-\mathrm{FDG}$ PET for monitoring therapeutic response is uncertain. Vascular tracer uptake is observed in a high proportion of patients with clinically inactive disease, as demonstrated in an observational study of 56 patients with LVV, where it may represent vessel wall remodelling, atherosclerosis, or another process besides active arteritis [71]. A discordance between clinical disease severity and vascular ${ }^{18} \mathrm{~F}$-FDG uptake after 6 months of biologic therapy for LVV was also highlighted in another study [72]. Moreover, in patients with LVV who require vascular surgery, peri-prosthetic graft uptake is commonly observed and appears unrelated to clinical disease activity, Creactive protein (CRP), or risk of subsequent disease progression [73]. For these reasons, there is a real clinical need for more specifically targeted PET ligands in the management of LVV [74].

As a chronic granulomatous disease, macrophages are a key component of the underlying disease process in LVV. One tracer that has previously been evaluated for imaging macrophage infiltration in LVV is the TSPO ligand ${ }^{11} \mathrm{C}-\mathrm{PK} 11195$ [75, 76]. In a study of 15 patients with clinically suspected active vasculitis or asymptomatic control subjects, increased ${ }^{11} \mathrm{C}-\mathrm{PK} 11195$ arterial uptake was observed in patients with active disease [76] (Fig. 1c). Macrophage $\mathrm{SST}_{2}$ PET imaging in LVV is the subject of an ongoing clinical study (clinical trials.gov: NCT04071691), for which the initial data appear promising. In the first clinical description of $\mathrm{SST}_{2} \mathrm{PET} / \mathrm{MRI}$ in patients with Takayasu arteritis from this ongoing study, ${ }^{68} \mathrm{Ga}$-DOTATATE and ${ }^{18} \mathrm{~F}-\mathrm{FET}-\beta \mathrm{AG}-$ TOCA accurately identified active arteritis in a patient with relapsing disease and another with treatment-resistant disease [77] (Fig. 1d).

\section{Targeting Specific Components of the Immune Response}

Research into novel PET tracers for imaging vascular inflammation has generated a wealth of encouraging data for a number of these approaches in atherosclerosis and LVV. Ultimately, PET imaging provides the opportunity to identify and characterise vascular lesions by phenotypic markers and processes relating to underlying inflammatory cell activity. For example, certain PET tracers are targeted to individual cell receptors on classically or alternatively activated macrophages known to be important at various stages in atherosclerotic plaque formation, rupture, and healing. However, the true selectively of many of these PET tracers for individual inflammatory cell types remains unknown. While important insights have been gained by studies attempting to answer this question using in vitro cell lines [78], ex vivo histological comparisons, and gene expression data to validate imaging findings, none of these experimental conditions can accurately replicate the in vivo environment. This is an important hurdle for future research in the field, which may be helped by advances in genomic methods such as single cell RNA sequencing and spatial transcriptomics. Indeed, the clinical translational value of novel tracers applied to examine individual components of the human immune response hinges on an ability to accurately 
understand the molecular and biological basis of PET signals, in order to apply valid clinical interpretation.

\section{PET Imaging as a Surrogate Marker of Drug Efficacy in Clinical Trials}

PET imaging has been applied in numerous clinical trials to examine the effects of cardiovascular therapies on vascular wall inflammation. For example, ${ }^{18}$ F-FDG PET has been used in the evaluation of cholesterol-lowering drugs such as statins and newer therapies that inhibit cholesteryl ester transfer protein, lipoprotein-associated phospholipase A2 (Lp-PLA2), p38 mitogen-activated protein kinase, and proprotein convertase subtilisin-kexin 9 (PCSK9) [79-83]. Overall, the results of these initial PET studies have been consistent with findings of subsequent larger clinical outcome trials [84]. For example, in a randomised placebo-controlled trial, dampening of carotid arterial ${ }^{18}$ F-FDG signals was observed after treatment with a PCSK9 inhibitor that is known to reduce cardiovascular risk through intensive low-density lipoprotein lowering, with a neutral effect on CRP [82]. In another single-arm pilot study, arterial ${ }^{18} \mathrm{~F}-\mathrm{FDG}$ uptake was reduced in individuals with treated human immunodeficiency virus and established cardiovascular disease or risk factors following a single injection of the IL-1 $\beta$ antagonist canakinumab [85]. Moreover, reductions in vascular inflammation have also been observed in clinical trials of patients treated for systemic inflammatory diseases associated with increased cardiovascular risk including diabetes, rheumatoid arthritis, psoriasis, and ankylosing spondylitis [86-89]. The results of observational ${ }^{18} \mathrm{~F}$-FDG PET studies involving drug interventions in LVV are discussed above.

Other PET tracers that may provide more precise markers of inflammation than ${ }^{18}$ F-FDG could have an advantage for tracking the effects of cardiovascular therapies longitudinally. ${ }^{68} \mathrm{Ga}-$ DOTATATE PET is currently being examined for use as an outcome measure in clinical trials of a PCSK9 inhibitor (clinicaltrials.gov: NCT04073810) and the diabetic medication semaglutide (clinicaltrials.gov: NCT04032197). Taking another approach, in a placebo-controlled study of dual anti-platelet therapy with ticagrelor in patients with multi-vessel coronary disease, ${ }^{18} \mathrm{~F}-\mathrm{NaF}$ PET imaging was used to select participants for inclusion on the basis of avid coronary tracer uptake [90•]. Although a negative study, this work exemplifies a potential role of PET imaging as a means of enriching high-risk patient populations in clinical trials before randomisation.

\section{PET Imaging for Identification and Stratification of High-Risk Patients}

As we sit on the brink of a new era of immune-targeted therapies for cardiovascular disease, PET imaging research can potentially help find new ways to identify patients with residual on-treatment vascular inflammation who would most benefit from newly emerging therapies. The landmark CANTOS

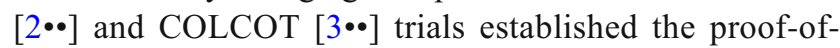
principle that immunomodulatory therapies can improve clinical outcomes in patients with atherosclerotic cardiovascular disease. Yet, other trials of anti-inflammatory agents, such as the Cardiovascular Inflammation Reduction Trial (CIRT) study of low-dose methotrexate, have not reached the same conclusion [91]. A key difference between these studies is that participants in CANTOS were selected on the basis of an elevated CRP, whereas those enrolled in CIRT had a low CRP. Compared with CRP, which although easy to measure represents a downstream marker of systemic inflammation or infection that is far removed from the affected tissue, PET imaging can provide a more direct measure of inflammation arising in the arterial wall.

In this context, PET imaging could either be used to further stratify select groups of high-risk patients or to help identify novel valid non-PET markers of inflammation. However, although a link between arterial inflammation and future cardiovascular risk identified by ${ }^{18}$ F-FDG PET can be implied through its association with clinical risk factors, serum biomarkers, high-risk plaque features, stroke recurrence, and major adverse clinical events in retrospective analyses of large PET imaging datasets [92-95], definitive prospective clinical outcome data is awaited. Studies linking increased arterial ${ }^{18}$ F-FDG uptake with adverse clinical outcomes in patients with psychological stress and chronic noise exposure provide further evidence that PET markers of inflammation can help identify high-risk patients [96, 97].

The prognostic potential of novel PET markers of inflammation and related pathological processes for predicting future cardiovascular events remains to be determined. A prospective study of 40 patients with symptomatic peripheral arterial disease found that PET imaging with both ${ }^{18} \mathrm{~F}$-FDG and ${ }^{18} \mathrm{~F}$ $\mathrm{NaF}$ was excellent for determining risk of restenosis following percutaneous femoral artery angioplasty [98]. Whether these findings are also applicable to coronary disease has yet to be tested. However, a post hoc analysis of prospective observational data from 293 patients showed that fatal and non-fatal myocardial infarction occurred only in patients with increased baseline coronary microcalcification as assessed by ${ }^{18} \mathrm{~F}-\mathrm{NaF}$ PET imaging during a 42-month follow-up period. In fact, ${ }^{18} \mathrm{~F}-\mathrm{NaF}$ PET imaging outperformed both clinical risk scores and coronary artery calcification scoring on receiver operator curve analysis in this study and was independently associated with a 7-fold increased risk in patients with the highest total coronary ${ }^{18} \mathrm{~F}-\mathrm{NaF}$ activity [99•]. The ability of coronary ${ }^{18} \mathrm{~F}$ $\mathrm{NaF}$ PET to predict recurrent events in patients with recent myocardial infarction and multi-vessel coronary disease is the subject of an ongoing prospective multi-centre clinical trial (clinicaltrials.gov: NCT02278211). 


\section{Conclusions}

Current uses of PET for imaging vascular inflammation in the clinic are limited. However, in the future, an ability to interrogate key components of vascular immune responses and systemic inflammatory pathways using PET with ${ }^{18} \mathrm{~F}-\mathrm{FDG}$ or novel tracers could help further the understanding of underlying disease mechanisms in atherosclerosis and vasculitis and inform the design or use of newly emerging immunomodulatory therapies in high-risk patient populations. Research efforts should continue if these roles are to be realised.

Funding Information Andrej Corović is supported by the Cambridge British Heart Foundation Centre of Research Excellence-funded Clinical Research Training Fellowship. Justin Mason acknowledges support from the NIHR Imperial Biomedical Research Centre. James Rudd is partsupported by the NIHR Cambridge Biomedical Research Centre, the BHF, HEFCE, the EPSRC, and the Wellcome Trust. Jason Tarkin is supported by the Wellcome Trust Clinical Research Career Development Fellowship (211100/Z/18/Z), the NIHR Imperial Biomedical Research Centre, and the Cambridge BHF Centre of Research Excellence.

\section{Compliance with Ethical Standards}

Conflict of Interest The authors declare that they have no conflict of interest.

Human and Animal Rights and Informed Consent The article is a review article; hence, there is no original experimental work; however, the article does reference other papers that have used humans and/or animals.

Open Access This article is licensed under a Creative Commons Attribution 4.0 International License, which permits use, sharing, adaptation, distribution and reproduction in any medium or format, as long as you give appropriate credit to the original author(s) and the source, provide a link to the Creative Commons licence, and indicate if changes were made. The images or other third party material in this article are included in the article's Creative Commons licence, unless indicated otherwise in a credit line to the material. If material is not included in the article's Creative Commons licence and your intended use is not permitted by statutory regulation or exceeds the permitted use, you will need to obtain permission directly from the copyright holder. To view a copy of this licence, visit http://creativecommons.org/licenses/by/4.0/.

\section{References}

Papers of particular interest, published recently, have been highlighted as:

- Of importance

•- Of major importance

1. Libby P, Loscalzo J, Ridker PM, Farkouh ME, Hsue PY, Fuster $\mathrm{V}$, et al. Inflammation, immunity, and infection in atherothrombosis JACC review topic of the week. J Am Coll Cardiol. 2018;72:2071-81.

2.• Ridker PM, Everett BM, Thuren T, et al. Antiinflammatory therapy with canakinumab for atherosclerotic disease. New Engl J Med.
2017;377:1119-31 Treatment with canakinumab, a monoclonal antibody targeting the interleukin-1 $\beta$ pathway, led to a significantly lower rate of recurrent cardiovascular events.

3.• Tardif J-C, Kouz S, Waters DD, et al. Efficacy and safety of lowdose colchicine after myocardial infarction. New Engl J Med. 2019;381:2497-505 Among patients with a recent myocardial infarction, treatment with low-dose colchicine led to a significantly lower risk of cardiovascular events.

4. Rudd JHF, Warburton EA, Fryer TD, Jones HA, Clark JC, Antoun $\mathrm{N}$, et al. Imaging atherosclerotic plaque inflammation with [ $18 \mathrm{~F}$ fluorodeoxyglucose positron emission tomography. Circulation. 2002;105:2708-11.

5. Tarkin JM, Joshi FR, Rudd JHF. PET imaging of inflammation in atherosclerosis. Nat Rev Cardiol. 2014;11:443-57.

6. Joseph P, Tawakol A. Imaging atherosclerosis with positron emission tomography. Eur Heart J. 2016;37:2974-80.

7. Cheng VY, Slomka PJ, Meunier LL, Tamarappoo BK, Nakazato R, Dey D, et al. Coronary arterial 18F-FDG uptake by fusion of PET and coronary $\mathrm{CT}$ angiography at sites of percutaneous stenting for acute myocardial infarction and stable coronary artery disease. J Nucl Med. 2012;53:575-83.

8. Joshi NV, Vesey AT, Williams MC, Shah ASV, Calvert PA, Craighead FHM, et al. 18F-fluoride positron emission tomography for identification of ruptured and high-risk coronary atherosclerotic plaques: a prospective clinical trial. Lancet. 2014;383:705-13.

9. Tarkin JM, Dweck MR, Evans NR, Takx RAP, Brown AJ, Tawakol A, et al. Imaging atherosclerosis. Circ Res. 2016;118: 750-69.

10. Gaemperli O, Shalhoub J, Owen DRJ, Lamare F, Johansson S, Fouladi N, et al. Imaging intraplaque inflammation in carotid atherosclerosis with 11C-PK11195 positron emission tomography/ computed tomography. Eur Heart J. 2011;33:1902-10.

11. Cuhlmann S, Gsell W, der Heiden KV, et al. In vivo mapping of vascular inflammation using the translocator protein tracer $18 \mathrm{~F}$ FEDAA1106. Mol Imaging. 2014;13:7290.2014.00014.

12. Hellberg S, Silvola JMU, Kiugel M, et al. 18-kDa translocator protein ligand 18F-FEMPA: biodistribution and uptake into atherosclerotic plaques in mice. J Nucl Cardiol. 2016;24:862-71.

13. Hellberg $\mathrm{S}$, Liljenbäck $\mathrm{H}$, Eskola $\mathrm{O}$, et al. Positron emission tomography imaging of macrophages in atherosclerosis with 18F-GE180 , a radiotracer for translocator protein (TSPO). Contrast Media Mol I. 2018;2018:9186902.

14. Rominger A, Saam T, Vogl E, Ubleis C, la Fougere C, Forster S, et al. In vivo imaging of macrophage activity in the coronary arteries using 68Ga-DOTATATE PET/CT: correlation with coronary calcium burden and risk factors. J Nucl Med. 2010;51:193-7.

15. Schatka I, Wollenweber T, Haense C, Brunz F, Gratz KF, Bengel FM. Peptide receptor-targeted radionuclide therapy alters inflammation in atherosclerotic plaques. J Am Coll Cardiol. 2013;62: 2344-5.

16. Li X, Samnick S, Lapa C, Israel I, Buck AK, Kreissl MC, et al. 68Ga-DOTATATE PET/CT for the detection of inflammation of large arteries: correlation with18F-FDG, calcium burden and risk factors. EJNMMI Res. 2012;2:52.

17. Mojtahedi A, Alavi A, Thamake S, Amerinia R, Ranganathan D, Tworowska I, et al. Assessment of vulnerable atherosclerotic and fibrotic plaques in coronary arteries using (68)Ga-DOTATATE PET/CT. Am J Nucl Med Mol Imaging. 2014;5:65-71.

18. Rinne P, Hellberg S, Kiugel M, Virta J, Li XG, Käkelä M, et al. Comparison of somatostatin receptor 2-targeting PET tracers in the detection of mouse atherosclerotic plaques. Mol Imaging Biol. 2016;18:99-108.

19. Tarkin JM, Joshi FR, Evans NR, et al. Detection of atherosclerotic inflammation by $68 \mathrm{Ga}$-DOTATATE PET compared to [18F]FDG PET imaging. J Am Coll Cardiol. 2017;69:1774-91 A study demonstrating that ${ }^{68} \mathrm{Ga}$-DOTATATE is better able to identify 
culprit versus non-culprit coronary lesions, with lower background myocardial signals, than ${ }^{18} \mathrm{~F}$-FDG.

20. Pedersen SF, Sandholt BV, Keller SH, Hansen AE, Clemmensen AE, Sillesen H, et al. 64Cu-DOTATATE PET/MRI for detection of activated macrophages in carotid atherosclerotic plaques: studies in patients undergoing endarterectomy. Arterioscler Thromb Vasc Biol. 2015;35:1696-703.

21. Malmberg C, Ripa RS, Johnbeck CB, Knigge U, Langer SW, Mortensen J, et al. 64Cu-DOTATATE for noninvasive assessment of atherosclerosis in large arteries and its correlation with risk factors: head-to-head comparison with $68 \mathrm{Ga}$-DOTATOC in 60 patients. J Nucl Med. 2015;56:1895-900.

22. Lee R, Kim J, Paeng JC, Byun JW, Cheon GJ, Lee DS, et al. Measurement of $68 \mathrm{Ga}$-DOTATOC uptake in the thoracic aorta and its correlation with cardiovascular risk. Nucl Med Mol Imaging. 2018;52:279-86.

23. Li X, Yu W, Wollenweber T, Lu X, Wei Y, Beitzke D, et al. [68Ga]Pentixafor PET/MR imaging of chemokine receptor 4 expression in the human carotid artery. Eur J Nucl Med Mol I. 2019;46:1616-25.

24. Weiberg D, Thackeray JT, Daum G, Sohns JM, Kropf S, Wester H$\mathrm{J}$, et al. Clinical molecular imaging of chemokine receptor CXCR4 expression in atherosclerotic plaque using (68)Ga-Pentixafor PET: correlation with cardiovascular risk factors and calcified plaque burden. J Nucl Med. 2017;59:266-72.

25. Derlin T, Sedding DG, Dutzmann J, et al. Imaging of chemokine receptor CXCR4 expression in culprit and nonculprit coronary atherosclerotic plaque using motion-corrected [68Ga]pentixafor PET/ CT. Eur J Nucl Med Mol I. 2018;45:1934-44 A study validating the utility of ${ }^{68}$ Ga-pentixafor for imaging coronary atherosclerotic inflammation.

26. Li X, Heber D, Leike T, et al. [68Ga]Pentixafor-PET/MRI for the detection of chemokine receptor 4 expression in atherosclerotic plaques. Eur J Nucl Med Mol I. 2017;45:558-66.

27. Kircher M, Tran-Gia J, Kemmer L, Zhang X, Schirbel A, Werner RA, et al. Imaging inflammation in atherosclerosis with CXCR4directed 68 Ga-Pentixafor PET/CT - correlation with 18 F-FDG PET/CT. J Nucl Med. 2019;61(5):751-6.

28. Hyafil F, Pelisek J, Laitinen I, Schottelius M, Mohring M, Döring $\mathrm{Y}$, et al. Imaging the cytokine receptor CXCR4 in atherosclerotic plaques with the radiotracer $68 \mathrm{Ga}$-Pentixafor for PET. J Nucl Med. 2017;58:499-506.

29. Liu Y, Pierce R, Luehmann HP, Sharp TL, Welch MJ. PET imaging of chemokine receptors in vascular injury-accelerated atherosclerosis. J Nucl Med. 2013;54:1135-41.

30. Luehmann HP, Pressly ED, Detering L, Wang C, Pierce R, Woodard PK, et al. PET/CT imaging of chemokine receptor CCR5 in vascular injury model using targeted nanoparticle. J Nucl Med. 2014;55:629-34.

31. Williams JW, Elvington A, Ivanov S, Kessler S, Luehmann H, Baba O, et al. Thermoneutrality but not UCP1 deficiency suppresses monocyte mobilization into blood. Circ Res. 2017;121: $662-76$.

32. Li W, Luehmann HP, Hsiao H-M, Tanaka S, Higashikubo R, Gauthier JM, et al. Visualization of monocytic cells in regressing atherosclerotic plaques by intravital 2-photon and positron emission tomography-based imaging-brief report. Arterioscler Thromb Vasc Biol. 2018;38:1030-6.

33. Luehmann HP, Detering L, Fors BP, Pressly ED, Woodard PK, Randolph GJ, et al. PET/CT imaging of chemokine receptors in inflammatory atherosclerosis using targeted nanoparticles. J Nucl Med. 2016;57:1124-9.

34. Silvola JMU, Li X-G, Virta J, Marjamäki P, Liljenbäck H, Hytönen $\mathrm{JP}$, et al. Aluminum fluoride-18 labeled folate enables in vivo detection of atherosclerotic plaque inflammation by positron emission tomography. Sci Rep. 2018;8:9720.
35. Kim EJ, Kim S, Seo HS, Lee YJ, Eo JS, Jeong JM, et al. Novel PET imaging of atherosclerosis with $68 \mathrm{Ga}$-labeled NOTAneomannosylated human serum albumin. J Nucl Med. 2016;57: 1792-7.

36. Tahara N, Mukherjee J, de Haas HJ, Petrov AD, Tawakol A, Haider $\mathrm{N}$, et al. 2-deoxy-2-[18F]fluoro-D-mannose positron emission tomography imaging in atherosclerosis. Nat Med. 2014;20:215-9.

37. Senders ML, Hernot S, Carlucci G, et al. Nanobody-facilitated multiparametric PET/MRI phenotyping of atherosclerosis. JACC Cardiovasc Imaging. 2018;12:2015-26.

38. Ye Y-X, Calcagno C, Binderup T, Courties G, Keliher EJ, Wojtkiewicz GR, et al. Imaging macrophage and hematopoietic progenitor proliferation in atherosclerosis. Circ Res. 2015;117: 835-45.

39. Bucerius J, Schmaljohann J, Böhm I, Palmedo H, Guhlke S, Tiemann K, et al. Feasibility of 18F-fluoromethylcholine PET/CT for imaging of vessel wall alterations in humans-first results. Eur J Nucl Med Mol I. 2008;35:815-20.

40. Hellberg S, Silvola JMU, Kiugel M, Liljenbäck H, Metsälä O, Viljanen T, et al. Type 2 diabetes enhances arterial uptake of choline in atherosclerotic mice: an imaging study with positron emission tomography tracer ${ }^{18} \mathrm{~F}$-fluoromethylcholine. Cardiovasc Diabetol. 2016;15:26.

41. Vöö S, Kwee RM, Sluimer JC, et al. Imaging intraplaque inflammation in carotid atherosclerosis with 18F-Fluorocholine positron emission tomography-computed tomography: prospective study on vulnerable atheroma with immunohistochemical validation. Circulation Cardiovasc Imaging. 2016;9:e004467.

42. Kato K, Schober O, Ikeda M, Schäfers M, Ishigaki T, Kies P, et al. Evaluation and comparison of 11C-choline uptake and calcification in aortic and common carotid arterial walls with combined PET/CT. Eur J Nucl Med Mol I. 2009;36:1622-8.

43. Majmudar MD, Yoo J, Keliher EJ, Truelove JJ, Iwamoto Y, Sena $\mathrm{B}$, et al. Polymeric nanoparticle PET/MR imaging allows macrophage detection in atherosclerotic plaques. Circ Res. 2013;112: 755-61.

44. Weissleder R, Nahrendorf M, Pittet MJ. Imaging macrophages with nanoparticles. Nat Mater. 2014;13:125-38.

45. Keliher EJ, Ye Y-X, Wojtkiewicz GR, Aguirre AD, Tricot B, Senders ML, et al. Polyglucose nanoparticles with renal elimination and macrophage avidity facilitate PET imaging in ischaemic heart disease. Nat Commun. 2017;8:14064.

46. Li X, Bauer W, Israel I, Kreissl MC, Weirather J, Richter D, et al. Targeting P-selectin by gallium-68-labeled fucoidan positron emission tomography for noninvasive characterization of vulnerable plaques. Arterioscler Thromb Vasc Biol. 2014;34:1661-7.

47. Nakamura I, Hasegawa K, Wada Y, Hirase T, Node K, Watanabe Y. Detection of early stage atherosclerotic plaques using PET and CT fusion imaging targeting P-selectin in low density lipoprotein receptor-deficient mice. Biochem Bioph Res Co. 2013;433:47-51.

48. Nahrendorf M, Keliher E, Panizzi P, Zhang H, Hembrador S, Figueiredo J-L, et al. 18F-4V for PET-CT imaging of VCAM-1 expression in atherosclerosis. JACC Cardiovasc Imaging. 2009;2: 1213-22.

49. Senders ML, Que X, Cho YS, Yeang C, Groenen H, Fay F, et al. PET/MR imaging of malondialdehyde-acetaldehyde epitopes with a human antibody detects clinically relevant atherothrombosis. J Am Coll Cardiol. 2018;71:321-35.

50. Pérez-Medina C, Binderup T, Lobatto ME, Tang J, Calcagno C, Giesen L, et al. In vivo PET imaging of HDL in multiple atherosclerosis models. JACC Cardiovasc Imaging. 2016;9:950-61.

51. Hyafil F, Tran-Dinh A, Burg S, Leygnac S, Louedec L, Milliner M, et al. Detection of apoptotic cells in a rabbit model with atherosclerosis-like lesions using the positron emission tomography radiotracer [18F]ML-10. Mol Imaging. 2015;14:7290.2015.00017. 
52. Moss AJ, Doris MK, Andrews JPM, et al. Molecular coronary plaque imaging using 18 F-fluoride. Circulation Cardiovasc Imaging. 2019;12:e008574.

53. van der Valk FM, Sluimer JC, Vöö SA, Verberne HJ, Nederveen $\mathrm{AJ}$, Windhorst AD, et al. In vivo imaging of hypoxia in atherosclerotic plaques in humans. JACC Cardiovasc Imaging. 2015;8:13401 .

54. Joshi FR, Manavaki R, Fryer TD, Figg NL, Sluimer JC, Aigbirhio FI, et al. Vascular imaging with (18)F-fluorodeoxyglucose positron emission tomography is influenced by hypoxia. J Am Coll Cardiol. 2017;69:1873-4.

55. Mateo J, Izquierdo-Garcia D, Badimon JJ, Fayad ZA, Fuster V. Noninvasive assessment of hypoxia in rabbit advanced atherosclerosis using ${ }^{18} \mathrm{~F}$-fluoromisonidazole positron emission tomographic imaging. Circulation Cardiovasc Imaging. 2014;7:312-20.

56. Nie X, Laforest R, Elvington A, Randolph GJ, Zheng J, Voller T, et al. PET/MRI of hypoxic atherosclerosis using 64Cu-ATSM in a rabbit model. J Nucl Med. 2016;57:2006-11.

57. Jenkins WS, Vesey AT, Vickers A, Neale A, Moles C, Connell M, et al. In vivo alpha- $\mathrm{V}$ beta-3 integrin expression in human aortic atherosclerosis. Heart. 2019;105:1868-75.

58. Beer AJ, Pelisek J, Heider P, Saraste A, Reeps C, Metz S, et al. PET/CT imaging of integrin $\alpha \mathrm{v} \beta 3$ expression in human carotid atherosclerosis. JACC Cardiovasc Imaging. 2014;7:178-87.

59. Laitinen I, Saraste A, Weidl E, Poethko T, Weber AW, Nekolla SG, et al. Evaluation of $\alpha \vee \beta 3$ integrin-targeted positron emission tomography tracer $18 \mathrm{~F}-$ Galacto-RGD for imaging of vascular inflammation in atherosclerotic mice. Circulation Cardiovasc Imaging. 2009;2:331-8.

60. Su H, Gorodny N, Gomez LF, Gangadharmath UB, Mu F, Chen G, et al. Atherosclerotic plaque uptake of a novel integrin tracer ${ }^{18} \mathrm{~F}$ flotegatide in a mouse model of atherosclerosis. J Nucl Cardiol. 2014;21:553-62.

61. Liu Y, Abendschein D, Woodard GE, Rossin R, McCommis K, Zheng J, et al. Molecular imaging of atherosclerotic plaque with 64Cu-labeled natriuretic peptide and PET. J Nucl Med. 2009;51: 85-91.

62. Liu Y, Pressly ED, Abendschein DR, Hawker CJ, Woodard GE, Woodard PK, et al. Targeting angiogenesis using a C-type atrial natriuretic factor-conjugated nanoprobe and PET. J Nucl Med. 2011;52:1956-63.

63. Bucerius J, Barthel H, Tiepolt S, Werner P, Sluimer JC, Wildberger JE, et al. Feasibility of in vivo $18 \mathrm{~F}$-florbetaben PET/MR imaging of human carotid amyloid- $\beta$. Eur J Nucl Med Mol I. 2017;44:1119-28.

64. Hellberg S, Silvola JMU, Liljenbäck H, Kiugel M, Eskola O, Hakovirta $\mathrm{H}$, et al. Amyloid-targeting PET tracer [18F]flutemetamol accumulates in atherosclerotic plaques. Molecules. 2019;24:1072.

65. Erbel R, Aboyans V, Boileau C, Bossone E, Bartolomeo RD, Eggebrecht H, et al. 2014 ESC guidelines on the diagnosis and treatment of aortic diseases. Eur Heart J. 2014;35:2873-926.

66. Dejaco C, Ramiro S, Duftner C, Besson FL, Bley TA, Blockmans $\mathrm{D}$, et al. EULAR recommendations for the use of imaging in large vessel vasculitis in clinical practice. Ann Rheum Dis. 2018;77: 636-43.

67. Slart RHJA, Glaudemans AWJM, Chareonthaitawee P, et al. FDGPET/CT(A) imaging in large vessel vasculitis and polymyalgia rheumatica: joint procedural recommendation of the EANM, SNMMI, and the PET interest group (PIG), and endorsed by the ASNC. Eur J Nucl Med Mol I. 2018;45:1250-69.

68. Lee S-W, Kim S-J, Seo Y, Jeong SY, Ahn B-C, Lee J. F-18 FDG PET for assessment of disease activity of large vessel vasculitis: a systematic review and meta-analysis. J Nucl Cardiol. 2019;26: $59-67$.
69. Nielsen BD, Gormsen LC, Hansen IT, Keller KK, Therkildsen P, Hauge E-M. Three days of high-dose glucocorticoid treatment attenuates large-vessel 18F-FDG uptake in large-vessel giant cell arteritis but with a limited impact on diagnostic accuracy. Eur J Nucl Med Mol I. 2018;45:1119-28.

70. Sammel AM, Hsiao E, Schembri G, Nguyen K, Brewer J, Schrieber L, et al. Diagnostic accuracy of positron emission tomography/ computed tomography of the head, neck, and chest for giant cell arteritis: a prospective, double-blind, cross-sectional study. Arthritis Rheum. 2019;71:1319-28.

71. Grayson PC, Alehashemi S, Bagheri AA, Civelek AC, Cupps TR, Kaplan MJ, et al. 18F-fluorodeoxyglucose-positron emission tomography as an imaging biomarker in a prospective, longitudinal cohort of patients with large vessel vasculitis. Arthritis Rheum. 2018;70:439-49.

72. Banerjee S, Quinn KA, Gribbons KB, Rosenblum JS, Civelek AC, Novakovich E, et al. Effect of treatment on imaging, clinical, and serologic assessments of disease activity in large-vessel vasculitis. J Rheumatol. 2019;47:99-107.

73. Youngstein T, Tombetti E, Mukherjee J, Barwick TD, al-Nahhas A, Humphreys E, et al. FDG uptake by prosthetic arterial grafts in large vessel vasculitis is not specific for active disease. JACC Cardiovasc Imaging. 2017;10:1042-52.

74. Hellmich B, Agueda A, Monti S, et al. 2018 update of the EULAR recommendations for the management of large vessel vasculitis. Ann Rheum Dis. 2019;79:19-30.

75. Lamare F, Hinz R, Gaemperli O, Pugliese F, Mason JC, Spinks T, et al. Detection and quantification of large-vessel inflammation with 11C-(R)-PK11195 PET/CT. J Nucl Med. 2010;52:33-9.

76. Pugliese F, Gaemperli O, Kinderlerer AR, Lamare F, Shalhoub J, Davies AH, et al. Imaging of vascular inflammation with [11C]PK11195 and positron emission tomography/computed tomography angiography. J Am Coll Cardiol. 2010;56:653-61.

77. Tarkin JM, Wall C, Gopalan D, et al. Novel approach to imaging active Takayasu arteritis using somatostatin receptor positron emission tomography/magnetic resonance imaging. Circulation Cardiovasc Imaging. 2020;13:e10389.

78. Borchert T, Beitar L, Langer LBN, Polyak A, Wester H-J, Ross TL, et al. Dissecting the target leukocyte subpopulations of clinically relevant inflammation radiopharmaceuticals. J Nucl Cardiol. 2019: $1-10$.

79. Singh P, Emami H, Subramanian S, et al. Coronary plaque morphology and the anti-inflammatory impact of atorvastatin. Circulation Cardiovasc Imaging. 2016;9:e004195.

80. Elkhawad M, Rudd JHF, Sarov-Blat L, Cai G, Wells R, Davies LC, et al. Effects of p38 mitogen-activated protein kinase inhibition on vascular and systemic inflammation in patients with atherosclerosis. JACC Cardiovasc Imaging. 2012;5:911-22.

81. Tawakol A, Singh P, Rudd JHF, Soffer J, Cai G, Vucic E, et al. Effect of treatment for 12 weeks with rilapladib, a lipoproteinassociated phospholipase A2 inhibitor, on arterial inflammation as assessed with $18 \mathrm{~F}$-fluorodeoxyglucose-positron emission tomography imaging. J Am Coll Cardiol. 2014;63:86-8.

82. Hoogeveen RM, Opstal TSJ, Kaiser Y, Stiekema LCA, Kroon J, Knol RJJ, et al. PCSK9 antibody alirocumab attenuates arterial wall inflammation without changes in circulating inflammatory markers. JACC Cardiovasc Imaging. 2019;12:2571-3.

83. Fayad ZA, Mani V, Woodward M, Kallend D, Abt M, Burgess T, et al. Safety and efficacy of dalcetrapib on atherosclerotic disease using novel non-invasive multimodality imaging (dal-PLAQUE): a randomised clinical trial. Lancet. 2011;378:1547-59.

84. Tarkin JM, Dweck MR, Rudd JHF. Imaging as a surrogate marker of drug efficacy in cardiovascular disease. Heart. 2018;105:567-78.

85. Hsue PY, Li D, Ma Y, Ishai A, Manion M, Nahrendorf M, et al. IL$1 \beta$ inhibition reduces atherosclerotic inflammation in HIV infection. J Am Coll Cardiol. 2018;72:2809-11. 
86. Mizoguchi M, Tahara N, Tahara A, Nitta Y, Kodama N, Oba T, et al. Pioglitazone attenuates atherosclerotic plaque inflammation in patients with impaired glucose tolerance or diabetes. JACC Cardiovasc Imaging. 2011;4:1110-8.

87. Mäki-Petäjä KM, Elkhawad M, Cheriyan J, Joshi FR, Östör AJK, Hall FC, et al. Anti-tumor necrosis factor- $\alpha$ therapy reduces aortic inflammation and stiffness in patients with rheumatoid arthritis. Circulation. 2012;126:2473-80.

88. Rivers JP, Powell-Wiley TM, Dey AK, et al. Visceral adiposity in psoriasis is associated with vascular inflammation by 18Fluorodeoxyglucose positron-emission tomography/computed tomography beyond cardiometabolic disease risk factors in an observational cohort study. JACC Cardiovasc Imaging. 2017;11:349-57.

89. van der Valk FM, Moens SJB, Verweij SL, Strang AC, Nederveen $\mathrm{AJ}$, Verberne HJ, et al. Increased arterial wall inflammation in patients with ankylosing spondylitis is reduced by statin therapy. Ann Rheum Dis. 2016;75:1848-51.

90. Moss AJ, Dweck MR, Doris MK, et al. Ticagrelor to reduce myocardial injury in patients with high-risk coronary artery plaque. JACC Cardiovasc Imaging. 2019. https://doi.org/10.1016/j.jcmg. 2019.05.023 This paper highlights the concept of using PET to identify "high-risk" individuals for inclusion in clinical trials.

91. Ridker PM, Everett BM, Pradhan A, MacFadyen J, Solomon DH, Zaharris E, et al. Low-dose methotrexate for the prevention of atherosclerotic events. New Engl J Med. 2019;380:752-62.

92. Kelly PJ, Camps-Renom P, Giannotti N, et al. Carotid plaque inflammation imaged by $18 \mathrm{~F}$-fluorodeoxyglucose positron emission tomography and risk of early recurrent stroke. Stroke. 2019;50: 1766-73.

93. Moon SH, Cho YS, Noh TS, Choi JY, Kim B-T, Lee K-H. Carotid FDG uptake improves prediction of future cardiovascular events in asymptomatic individuals. JACC Cardiovasc Imaging. 2015;8: 949-56.

94. Figueroa AL, Abdelbaky A, Truong QA, Corsini E, MacNabb M, Lavender ZR, et al. Measurement of arterial activity on routine FDG PET/CT images improves prediction of risk of future CV events. JACC Cardiovasc Imaging. 2013;6:1250-9.

95. Fernández-Friera L, Fuster V, López-Melgar B, Oliva B, SánchezGonzález J, Macías A, et al. Vascular inflammation in subclinical atherosclerosis detected by hybrid PET/MRI. J Am Coll Cardiol. 2019;73:1371-82.

96. Tawakol A, Ishai A, Takx RA, et al. Relation between resting amygdalar activity and cardiovascular events: a longitudinal and cohort study. Lancet. 2017;389:834-45.

97. Osborne MT, Radfar A, Hassan MZO, et al. A neurobiological mechanism linking transportation noise to cardiovascular disease in humans. Eur Heart J. 2019;41:772-82.

98. Chowdhury MM, Tarkin JM, Albaghdadi MS, et al. Vascular positron emission tomography and restenosis in symptomatic peripheral arterial disease a prospective clinical study. JACC Cardiovasc Imaging. 2019;13:1008-17.

99. Kwiecinski J, Tzolos E, Adamson PD, et al. Coronary 18F-sodium fluoride uptake predicts outcomes in patients with coronary artery disease. J Am Coll Cardiol. 2020;75:3061-74 This paper showed that coronary microcalcification assessed by ${ }^{18} \mathrm{~F}-\mathrm{NaF}$ PET imaging was associated with significantly increased risk of subsequent clinical events, using both the standard tissue-tobackground ratio and a novel total coronary artery microcalcification score.

Publisher's Note Springer Nature remains neutral with regard to jurisdictional claims in published maps and institutional affiliations. 